\title{
Adsorption Properties of MFM-400 and MFM-401 with CO2 and Hydrocarbons: Selectivity Derived from Directed Supramolecular Interactions
}

DOI:

10.1021/acs.inorgchem.6b00035

\section{Document Version}

Final published version

Link to publication record in Manchester Research Explorer

Citation for published version (APA):

Ibarra, I., Mace, A., Yang, S., Sun, J., Lee, S., Chang, J-S., Laaksonen, A., Schröder, M., \& Zou, X. (2016).

Adsorption Properties of MFM-400 and MFM-401 with CO2 and Hydrocarbons: Selectivity Derived from Directed Supramolecular Interactions. Inorganic Chemistry: including bioinorganic chemistry, 55(15), 7219-7228.

https://doi.org/10.1021/acs.inorgchem.6b00035

\section{Published in:}

Inorganic Chemistry: including bioinorganic chemistry

\section{Citing this paper}

Please note that where the full-text provided on Manchester Research Explorer is the Author Accepted Manuscript or Proof version this may differ from the final Published version. If citing, it is advised that you check and use the publisher's definitive version.

\section{General rights}

Copyright and moral rights for the publications made accessible in the Research Explorer are retained by the authors and/or other copyright owners and it is a condition of accessing publications that users recognise and abide by the legal requirements associated with these rights.

\section{Takedown policy}

If you believe that this document breaches copyright please refer to the University of Manchester's Takedown Procedures [http://man.ac.uk/04Y6Bo] or contact uml.scholarlycommunications@manchester.ac.uk providing relevant details, so we can investigate your claim.

\section{OPEN ACCESS}




\title{
Adsorption Properties of MFM-400 and MFM-401 with $\mathrm{CO}_{2}$ and Hydrocarbons: Selectivity Derived from Directed Supramolecular Interactions
}

\author{
Ilich A. Ibarra,,$^{\dagger,}$ Amber Mace, ${ }^{\dagger}$ Sihai Yang, ${ }^{\S, \|}$ Junliang Sun, ${ }^{\dagger}$ Sukyung Lee, ${ }^{\perp}$ Jong-San Chang, ${ }^{\perp, \#}$ \\ Aatto Laaksonen, ${ }^{\dagger}$ Martin Schröder, ${ }^{*}, \S^{\prime} \|$ and Xiaodong Zou ${ }^{*}{ }^{\dagger}$ \\ ${ }^{\dagger}$ Berzelii Centre EXSELENT on Porous Materials, and Department of Materials and Environmental Chemistry, Stockholm \\ University, SE-106 91 Stockholm, Sweden \\ ${ }^{\ddagger}$ Instituto de Investigaciones en Materiales, Universidad Nacional Autónoma de México, Circuito Exterior s/n, CU, Del. Coyoacán, \\ 04510 Mexico, DF, Mexico \\ ${ }^{\S}$ School of Chemistry, University of Nottingham, Nottingham NG7 2RD, U.K. \\ "School of Chemistry, University of Manchester, Manchester M13 9PL, U.K. \\ ${ }^{\perp}$ Catalysis Center for Molecular Engineering, Korea Research Institute of Chemical Technology (KRICT), P.O. Box 107, Yusung, \\ Daejon 305-600, Korea \\ \#Department of Chemistry, Sungkyunkwan University, Suwon 440-476, Korea
}

\section{Supporting Information}

ABSTRACT: $\left(\left[\mathrm{Sc}_{2}(\mathrm{OH})_{2}(\mathrm{BPTC})\right]\right)\left(\mathrm{H}_{4} \mathrm{BPTC}=\right.$ biphenyl-3,3',5,5' -tetracarboxylic acid), MFM$400(\mathrm{MFM}=$ Manchester Framework Material, previously designated NOTT), and $([\mathrm{Sc}(\mathrm{OH})$ (TDA)]) $\left(\mathrm{H}_{2} \mathrm{TDA}=\right.$ thiophene-2,5-dicarboxylic acid), MFM-401, both show selective and reversible capture of $\mathrm{CO}_{2}$. In particular, MFM-400 exhibits a reasonably high $\mathrm{CO}_{2}$ uptake at low pressures and competitive $\mathrm{CO}_{2} / \mathrm{N}_{2}$ selectivity coupled to a moderate isosteric heat of adsorption $\left(Q_{\mathrm{st}}\right)$ for $\mathrm{CO}_{2}\left(29.5 \mathrm{~kJ} \mathrm{~mol}^{-1}\right)$ at zero coverage, thus affording a facile uptake-release process. Grand canonical Monte Carlo (GCMC) and density functional theory (DFT) computational analyses of $\mathrm{CO}_{2}$ uptake in both materials confirmed preferential adsorption sites consistent with the higher $\mathrm{CO}_{2}$ uptake observed experimentally for MFM-400 over MFM-401 at low pressures. For MFM-400, the Sc-OH group participates in moderate interactions with $\mathrm{CO}_{2}\left(Q_{\mathrm{st}}=33.5 \mathrm{~kJ}\right.$ $\left.\mathrm{mol}^{-1}\right)$, and these are complemented by weak hydrogen-bonding interactions $(\mathrm{O} \cdots \mathrm{H}-\mathrm{C}=3.10-$ $3.22 \AA$ ) from four surrounding aromatic $-\mathrm{CH}$ groups. In the case of MFM-401, adsorption is provided by cooperative interactions of $\mathrm{CO}_{2}$ with the $\mathrm{Sc}-\mathrm{OH}$ group and one $\mathrm{C}-\mathrm{H}$ group. The binding energies obtained by DFT analysis for the adsorption sites for both materials correlate
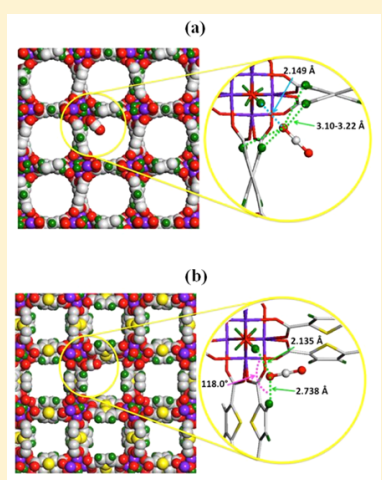
well with the observed moderate isosteric heats of adsorption for $\mathrm{CO}_{2}$. GCMC simulations for both materials confirmed higher uptake of EtOH compared with nonpolar vapors of toluene and cyclohexane. This is in good correlation with the experimental data, and DFT analysis confirmed the formation of a strong hydrogen bond between EtOH and the hydrogen atom of the hydroxyl group of the MFM-400 and MFM-401 framework (FW) with $\mathrm{H}-\mathrm{O}_{\mathrm{EtOH}} \cdots \mathrm{H}-\mathrm{O}_{\mathrm{FW}}$ distances of 1.77 and $1.75 \AA$, respectively. In addition, the accessible regeneration of MFM-400 and MFM-401 and release of $\mathrm{CO}_{2}$ potentially provide minimal economic and environmental penalties.

\section{INTRODUCTION}

Air pollution and global warming are two of the greatest threats to human civilization. Of particular relevance are the rising levels of anthropogenic carbon dioxide $\left(\mathrm{CO}_{2}\right)$ and industrial gas and vapor emissions, which are directly impacting our environment, causing the increase of temperature across the planet. ${ }^{1}$ Thus, the drastic reduction of these $\mathrm{CO}_{2}$ levels is essential in order to minimize the risk that the greenhouse gas effect represents to our society.

At present, the absorption of $\mathrm{CO}_{2}$ by aqueous solutions of amines (taking advantage of the Lewis acidity of $\mathrm{CO}_{2}$ ) is widely used. However, their major limitations, such as thermal stability, corrosion of pipelines, and the significant costs associated with the extensive energy input required for their regeneration, considerably limit their long-term application. ${ }^{1,2}$ The design and synthesis of materials that demonstrate high selectivity and reversible regeneration at an economically viable cost for gas capture remain a major challenge for critical applications such as the selective and reversible capture of $\mathrm{CO}_{2}$ and organic vapors. ${ }^{2,3}$

Porous metal-organic frameworks (MOFs) are among the most promising candidates for gas storage and separation

Special Issue: Metal-Organic Frameworks for Energy Applications

Received: January 6, 2016

Published: March 31, 2016 
because their sorption selectivity toward small-molecule adsorbates is directly tunable as a function of the topology and chemical composition of the micropores. ${ }^{4}$ In the field of gas capture, there is an emphasis on optimizing the interactions between the MOF material and the adsorbed gas molecules, leading to the discovery of new functional porous materials with enhanced capture properties. ${ }^{4 \mathrm{~h}, \mathrm{i}}$ Consequently, the identification of preferred adsorption sites within a pore structure represents a very important strategy in order to understand the mechanisms for efficient and selective capture of $\mathrm{CO}_{2}$.

Porous metal-organic materials with high surface area and pore volume normally show high $\mathrm{CO}_{2}$ storage capacities at room temperature and relatively high pressures. ${ }^{5}$ As an example, MOF177 possesses a Brunauer-Emmett-Teller (BET) surface area of $4500 \mathrm{~m}^{2} \mathrm{~g}^{-1}$ and a $\mathrm{CO}_{2}$ storage capacity of $60.8 \mathrm{wt} \%$ at $298 \mathrm{~K}$ and 35 bar. $^{.}$However, at $298 \mathrm{~K}$ and 1 bar, the storage capacity of this material corresponds to $3.4 \mathrm{wt} \%{ }^{6}$ Additionally, MOF-177 exhibits $^{1 \mathrm{~b}}$ a selectivity for $\mathrm{CO}_{2}$ over $\mathrm{N}_{2}$ of $\alpha=4\left(\alpha=\mathrm{CO}_{2} / \mathrm{N}_{2}\right)$, calculated using the $\mathrm{CO}_{2}$ uptake $\left(n_{\mathrm{CO}_{2}}\right)$ at 0.15 bar and the $\mathrm{N}_{2}$ uptake $\left(n_{\mathrm{N}_{2}}\right)$ at 0.85 bar. ${ }^{1 \mathrm{~b}}$ Currently, common synthetic strategies aimed at enhancing host-guest interactions in these systems involve the introduction of open metal sites ${ }^{7}$ and decoration of the pores with (Lewis) basic nitrogen-containing groups such as triazole, ${ }^{8}$ amine,${ }^{8 a, 9}$ and tetrazole. ${ }^{10}$ Materials such as MIL-100 and MIL-101 exhibit high surface areas and large pore sizes in addition to open metal sites based upon $\mathrm{Cr}$ (III) centers. ${ }^{11}$ Both materials show high capacity for $\mathrm{CO}_{2}$ and high isosteric enthalpies of adsorption $\left(Q_{s t}\right)$ for $\mathrm{CO}_{2}(44$ and $63 \mathrm{~kJ}$ $\mathrm{mol}^{-1}$ for MIL-100 and MIL-101, respectively). Woo and coworkers reported ${ }^{9}$ the direct observation of $\mathrm{CO}_{2}$ in an aminefunctionalized material with a relatively high enthalpy of adsorption for $\mathrm{CO}_{2}$, calculated to be $\sim 40 \mathrm{~kJ} \mathrm{~mol}^{-1}$. Long and co-workers functionalized a triazolate-bridged material with ethylenediamine and reported a very high $Q_{\mathrm{st}}$ for $\mathrm{CO}_{2}(90 \mathrm{~kJ}$ $\left.\mathrm{mol}^{-1}\right){ }^{8 \mathrm{a}}$ The enhancement of these gas-framework interactions is clearly related to the increase in $Q_{s t}$. However, a very high isosteric heat of adsorption $\left(40-90 \mathrm{~kJ} \mathrm{~mol}^{-1}\right.$ for $\mathrm{CO}_{2}$ physisorption) results in a considerable energy penalty upon desorption of $\mathrm{CO}_{2}$.

Suitable choices of the metal cation nodes and organic ligands for the construction of porous hosts and adjustment of the pore shape and size to increase the overlapping energy potential of the pore walls ${ }^{1 \mathrm{~b}, 7,12}$ can greatly favor selectivity for $\mathrm{CO}_{2}$. In this study, we examined two materials, MFM-400 and MFM-401 (Scheme 1), ${ }^{13}$ that are based upon a binuclear $\left[\mathrm{Sc}_{2}\left(\mu_{2}-\mathrm{OH}\right)\right]$ building block and show high thermal stabilities and relatively modest surface areas $\left(\sim 1400 \mathrm{~m}^{2} \mathrm{~g}^{-1}\right)$. We report for the first time the $\mathrm{CO}_{2}$ adsorption properties of MFM-400 and MFM-401 as well as calculations detailing and defining the $\mathrm{CO}_{2}$ binding in these systems consistent with the observed competitive $\mathrm{CO}_{2} / \mathrm{N}_{2}$ selectivity.

\section{EXPERIMENTAL SECTION}

Chemicals. $\mathrm{Sc}\left(\mathrm{SO}_{3} \mathrm{CF}_{3}\right)_{3} \cdot x \mathrm{H}_{2} \mathrm{O}$, biphenyl-3,3',5,5'-tetracarboxylic acid $\left(\mathrm{H}_{4} \mathrm{BPTC}\right){ }^{4 \mathrm{e}}$ thiophene-2,5-dicarboxylic acid ( $\left.\mathrm{H}_{2} \mathrm{TDA}\right), \mathrm{N}, \mathrm{N}$ dimethylformamide (DMF), and tetrahydrofuran (THF) were purchased from Sigma-Aldrich or Fisher Scientific and used as received.

Material Synthesis. MFM-400 $\left(\left[\mathrm{Sc}_{2}(\mathrm{OH})_{2}(\mathrm{BPTC})\right]\right)$ and MFM$401([\mathrm{Sc}(\mathrm{OH})(\mathrm{TDA})])$ were synthesized according to procedures previously reported. ${ }^{13}$

Material Activation. Samples of as-synthesized solvated MFM-400 and MFM- 401 were placed in acetone for 4 days followed by degassing at $170^{\circ} \mathrm{C}$ and $10^{-10}$ bar for $12 \mathrm{~h}$ to afford the fully desolvated materials.
Scheme 1. Views of the Coordination at Sc(III) in (a) MFM400, Showing [BPTC] ${ }^{4-}$ and the $\mu_{2}-\mathrm{OH}$ Group, and (b) MFM-401, Showing [TDA $]^{2-}$ and the $\mu_{2}-\mathrm{OH}$ Group

(a)

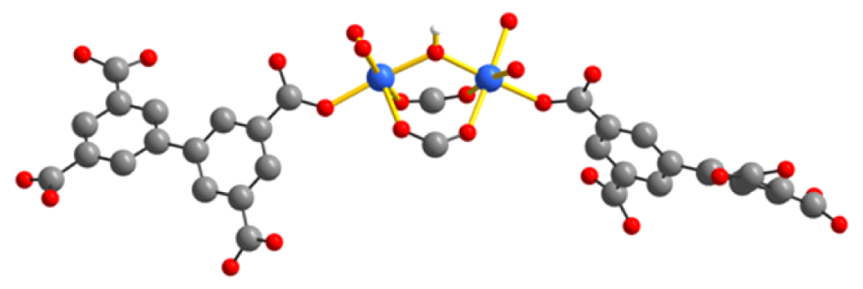

(b)

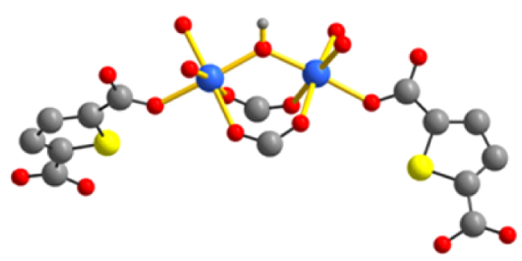

Adsorption Isotherms for $\mathrm{CO}_{2}, \mathrm{CH}_{4}, \mathrm{~N}_{2}$, EtOH, Toluene, and Cyclohexane. $\mathrm{CO}_{2}, \mathrm{CH}_{4}$, and $\mathrm{N}_{2}$ isotherms (up to 1 bar) were recorded on a Micromeritics ASAP2020 analyzer at Stockholm University under ultrahigh vacuum in a clean system with a diaphragm and turbo pumping system. Isotherms for $\mathrm{CO}_{2}$ and $\mathrm{CH}_{4}$ up to $20 \mathrm{bar}$ and $\mathrm{EtOH}$, toluene, and cyclohexane up to 1 bar were recorded on an IGA system (Hiden Isochema) at the Korea Research Institute of Chemical Technology. Ultrapure grade (99.9995\%) $\mathrm{CO}_{2}, \mathrm{CH}_{4}$, and $\mathrm{N}_{2}$ were purchased from PRAXAIR.

\section{RESULTS AND DISCUSSION}

Gas Adsorption Properties. $\mathrm{N}_{2}$ adsorption isotherms for both activated materials, MFM-400a and MFM-401a (where the label "a" represents the activated desolvated material), at $77 \mathrm{~K}$ were used to calculate the surface areas and pore volumes of the samples. BET surface area calculations were conducted over a pressure range of $0.008<p / p_{0}<0.038$, which satisfied the two major criteria established by Rouquerol et al. ${ }^{14}$ for microporous materials (zeolites and microporous carbon) and corroborated by Walton and Snurr ${ }^{15}$ for MOFs for surface area determination. The results are presented in Table $S 1$ in the Supporting Information. The BET surface areas and pore volumes for MFM400a and MFM-401a were measured and found to be identical to the values reported previously. ${ }^{13}$

Adsorption experiments using different probe analytes $\left(\mathrm{CO}_{2}\right.$, $\mathrm{CH}_{4}$, and $\mathrm{N}_{2}$ ) were carried out on freshly prepared samples of MFM-400a and MFM-401a. At low pressure (1 bar), MFM-400a shows $\mathrm{CO}_{2}$ capacities with a maximum uptake of $7.9 \mathrm{mmol} \mathrm{g}^{-1}$ at $273 \mathrm{~K}$ (Figure S1 in the Supporting Information), and at $293 \mathrm{~K}$ and 1 bar the total uptake is $4.9 \mathrm{mmol} \mathrm{g}^{-1}$. Interestingly, this $\mathrm{CO}_{2}$ isotherm shows a linear uptake (Figure 1a inset) with no indication of saturation before reaching 1 bar; a higher-pressure experiment ( 20 bar, $293 \mathrm{~K}$ ) was therefore carried out. The linear uptake region was found to extend to over 2 bar, while saturation was achieved at $20 \mathrm{bar}$, corresponding to approximately 10.2 mmol g ${ }^{-1}$ (Figure 1a).

For MFM-401a, the total $\mathrm{CO}_{2}$ uptake at 1 bar was measured as $5.5 \mathrm{mmol} \mathrm{g}^{-1}$ at $273 \mathrm{~K}$ (Figure S2) and $2.9 \mathrm{mmol} \mathrm{g}^{-1}$ at $293 \mathrm{~K}$. As for MFM-400a, MFM-401a shows a linear uptake up to 1 bar (Figure $1 \mathrm{~b}$ inset), and in the higher-pressure experiment (20 bar, $293 \mathrm{~K})$ this linear uptake was found to extend to $\sim 3$ bar. Saturation was achieved at 20 bar, corresponding to approx- 

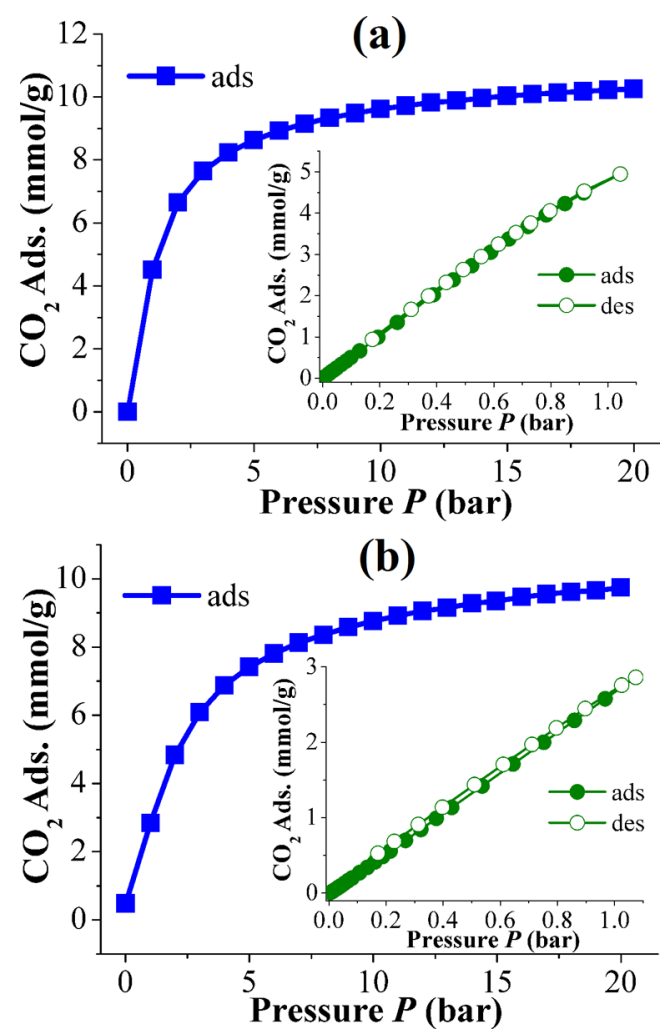

Figure 1. Adsorption isotherms for $\mathrm{CO}_{2}$ in (a) MFM-400a and (b) MFM-401a up to 20 bar at $293 \mathrm{~K}$. The insets show the $\mathrm{CO}_{2}$ sorption isotherms at low pressure.

imately $9.7 \mathrm{mmol} \mathrm{g}^{-1}$ (Figure $1 \mathrm{~b}$ ). Table 1 summarizes the gas adsorption data.

At low pressure (1 bar), MFM-400a shows a higher $\mathrm{CO}_{2}$ uptake than MFM-401a even though the surface area of MFM$401 \mathrm{a}\left(1512 \mathrm{~m}^{2} \mathrm{~g}^{-1}\right)$ is higher than that of MFM-400a $\left(1354 \mathrm{~m}^{2}\right.$ $\mathrm{g}^{-1}$ ). However, at 20 bar the $\mathrm{CO}_{2}$ isotherms for both materials reach saturation (Figure 1), and therefore, the uptakes are very similar for MFM-400a and MFM-401a (10.2 and $9.7 \mathrm{mmol} \mathrm{g}^{-1}$, respectively). These results suggest that at low pressure MFM400a has a greater $\mathrm{CO}_{2}$ uptake than MFM-401a, and this is supported by grand canonical Monte Carlo (GCMC) simulations (vide infra).

Motivated by the $\mathrm{CO}_{2}$ capacities shown by MFM-400 and MFM-401, we decided to explore the $\mathrm{CH}_{4}$ sequestration properties of these materials. Thus, samples of MFM-400a and MFM-401a were tested for $\mathrm{CH}_{4}$ adsorption at ambient temperatures and two different pressures ( 1 and $20 \mathrm{bar}$ ), and these results are summarized in Table 1 . At $293 \mathrm{~K}$ and 1 bar, the total uptake for MFM-400 is $0.8 \mathrm{mmol} \mathrm{g}^{-1}$ and the uptake shows linearity within the measured range (Figure 2a inset). This uptake is higher than for the isostructural MFM-300a(Al) which showed a total uptake of $0.3 \mathrm{mmol} \mathrm{g}^{-1}$ at $293 \mathrm{~K}^{16 \mathrm{a}}$ This is probably due to diffusion effects, as observed previously. ${ }^{16 \mathrm{~b}}$ The linear uptake region extends to $\sim 4 \mathrm{bar}$, and the total uptake at 20
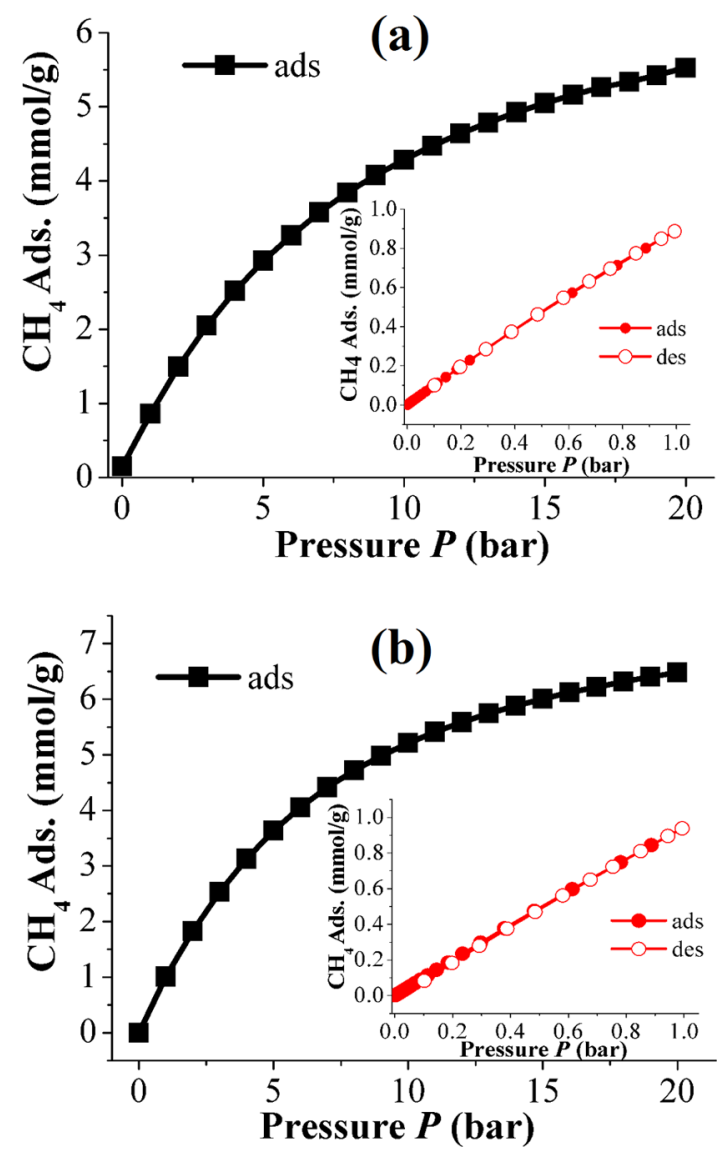

Figure 2. Adsorption isotherms for $\mathrm{CH}_{4}$ in (a) MFM-400a and (b) MFM-401a up to 20 bar at $293 \mathrm{~K}$. The insets show the $\mathrm{CH}_{4}$ sorption isotherms at low pressure (up to $1 \mathrm{bar}$ ).

bar is $5.5 \mathrm{mmol} \mathrm{g}^{-1}$ with saturation not reached (Figure 2a). MFM-401a shows a total uptake of $0.9 \mathrm{mmol} \mathrm{g}^{-1}$ at $293 \mathrm{~K}$ and 1 bar (Figure $2 \mathrm{~b}$ inset), and the linear uptake region extends to about 4 bar. The total uptake at 20 bar is $6.5 \mathrm{mmol} \mathrm{g}^{-1}$ with saturation not reached (Figure $2 \mathrm{~b}$ ). At low pressure ( 1 bar) and ambient temperatures (273 and $293 \mathrm{~K}$ ), the $\mathrm{CH}_{4}$ uptakes for MFM-400a and MFM-401a are identical, suggesting that at low pressure there is no apparent special affinity for $\mathrm{CH}_{4}$ in either system. At 20 bar and $293 \mathrm{~K}$, with saturation not reached (Figure 2), MFM-401a shows a higher $\mathrm{CH}_{4}$ uptake $\left(6.5 \mathrm{mmol} \mathrm{g}^{-1}\right)$ than MFM-400a $\left(5.5 \mathrm{mmol} \mathrm{g}^{-1}\right)$, which is in good agreement with the observed higher surface area of MFM-401a. Thus, the $\mathrm{CH}_{4}$ uptakes in MFM-400a and MFM-401a are consistent with those of previously reported porous MOFs. ${ }^{1}$

Vapor Adsorption Properties. Adsorption isotherms for $\mathrm{EtOH}$, toluene, and cyclohexane in MFM-400a and MFM-401a were measured (Figure 3). These analytes were specifically chosen to allow comparison of preferential host-guest interactions within the pores for both materials. Thus, the relative hydrophilicity/hydrophobicity was established for MFM-400a and MFM-401a by vapor sorption of EtOH versus

Table 1. Gas Adsorption Data for MFM-400a and MFM-401a

\begin{tabular}{|c|c|c|c|c|c|c|c|c|}
\hline \multirow[b]{2}{*}{ sample } & \multicolumn{3}{|c|}{$\mathrm{CO}_{2}$ uptake $\left(\mathrm{mmol} \mathrm{g}^{-1}\right)$} & \multicolumn{3}{|c|}{$\mathrm{CH}_{4}$ uptake $\left(\mathrm{mmol} \mathrm{g}^{-1}\right)$} & \multicolumn{2}{|c|}{$Q_{\mathrm{st}}\left(\mathrm{kJ} \mathrm{mol}{ }^{-1}\right)$} \\
\hline & 1 bar, $273 \mathrm{~K}$ & 1 bar, $293 \mathrm{~K}$ & 20 bar, $293 \mathrm{~K}$ & 1 bar, $273 \mathrm{~K}$ & 1 bar, $293 \mathrm{~K}$ & 20 bar, $293 \mathrm{~K}$ & $\mathrm{CO}_{2}$ & $\mathrm{CH}_{4}$ \\
\hline MFM-400a & 7.9 & 4.9 & 10.2 & 1.1 & 0.8 & 5.5 & 29.5 & 16.6 \\
\hline MFM-401a & 5.5 & 2.9 & 9.7 & 1.1 & 0.9 & 6.5 & 36.5 & 18.3 \\
\hline
\end{tabular}



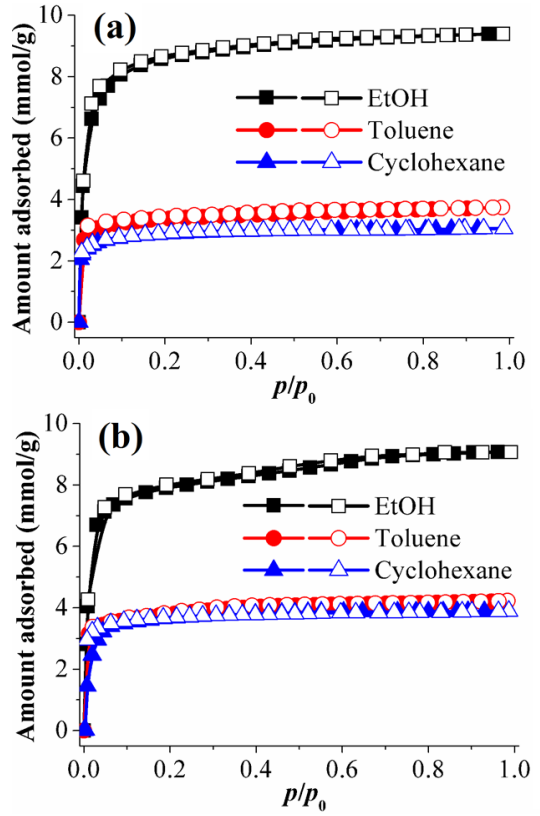

Figure 3. Adsorption isotherms for $\mathrm{EtOH}$, toluene, and cyclohexane vapors in (a) MFM-400a and (b) MFM-401a up to 1 bar and $298 \mathrm{~K}$.

apolar aromatics (toluene and cyclohexane). Uptake of EtOH, toluene, and cyclohexane is rapid at low pressure and shows a characteristic Type-I isotherm (Figure 3). Saturation is reached in the low-pressure region $\left(p / p_{0}<0.02\right)$, indicative of strong host-guest interactions in all cases. Interestingly, in both cases the EtOH adsorption was considerably higher than that of toluene or cyclohexane, reflecting the size and polarity of EtOH. The kinetic diameter of EtOH is approximately $4.5 \AA$, which is considerably smaller than those of toluene $(5.9 \AA)$ and cyclohexane $(6.0 \AA)$, and therefore, it is not surprising that lower quantities of toluene and cyclohexane are adsorbed. The vapor uptakes for MFM-400a at 1 bar and $298 \mathrm{~K}$ (Figure 3a) are $9.4 \mathrm{mmol} \mathrm{g}^{-1}$ for EtOH, $3.7 \mathrm{mmol} \mathrm{g}^{-1}$ for toluene, and $3.1 \mathrm{mmol}$ $\mathrm{g}^{-1}$ for cyclohexane. In the case of MFM-401a at 1 bar and $298 \mathrm{~K}$ (Figure 3b), the uptakes of EtOH, toluene, and cyclohexane are 9.1, 4.2, and $3.9 \mathrm{mmol} \mathrm{g}^{-1}$, respectively. The strength of the interactions of guest molecules with the porous host material can depend on several factors. EtOH is capable of hydrogen-bonding interactions with the host porous material, while toluene is likely to participate in $\pi-\pi$ interactions with the ligands in the framework. Cyclohexane is relatively inert in a supramolecular sense, leading to a lower uptake than for $\mathrm{EtOH}$ and toluene. GCMC and density functional theory (DFT) computational analyses were employed to predict the binding sites of $\mathrm{EtOH}$, toluene, and cyclohexane in these materials (vide infra).

Yang et al. ${ }^{16 \mathrm{~b}}$ reported the direct visualization of $\mathrm{CO}_{2}$ in the $\mathrm{Al}(\mathrm{III})$-based material MFM-300a(Al). In situ powder X-ray diffraction and inelastic neutron studies combined with modeling identified the binding sites for $\mathrm{CO}_{2}$ within this material. Interestingly, as mentioned above, MFM-300a(Al) $\left(\left[\mathrm{Al}_{2}(\mathrm{OH})_{2}(\mathrm{BPTC})\right]\right)$ is isostructural to MFM-400a $\left(\left[\mathrm{Sc}_{2}(\mathrm{OH})_{2}(\mathrm{BPTC})\right]\right)$, with both frameworks being based on binuclear $\left[\mathrm{M}_{2}\left(\mu_{2}-\mathrm{OH}\right)\right]$ moieties bridged by the isophthalate tetracarboxylate ligand $\mathrm{BPTC}^{4-}$. MFM-300a(Al) and MFM400 a both show high thermal stability up to 400 and $520^{\circ} \mathrm{C}$, respectively. MFM-300a(Al) shows a BET surface area of 1370 $\mathrm{m}^{2} \mathrm{~g}^{-1}$, a pore volume of $0.37 \mathrm{~cm}^{3} \mathrm{~g}^{-1}$, and a total $\mathrm{CO}_{2}$ uptake of $7.0 \mathrm{mmol} \mathrm{g}^{-1}$ at $273 \mathrm{~K}$ and $1 \mathrm{bar}$. Thus, as well as sharing the same structure and exhibiting similar thermal stabilities, surface areas, and pore volumes, these two materials exhibit similar $\mathrm{CO}_{2}$ uptakes $\left(7.9 \mathrm{mmol} \mathrm{g}^{-1}\right.$ at $273 \mathrm{~K}$ and 1 bar for MFM-400a). We have used GCMC and DFT computational analyses to predict the binding sites of $\mathrm{CO}_{2}$ in MFM-400a. The procedures used are described below.

In addition, in order to identify the preferred binding sites for $\mathrm{CO}_{2}$ inside MFM-400a and MFM-401a, we performed in situ synchrotron PXRD analysis. In the case of MFM-400a, the lowangle diffraction peaks (see Figures S5 and S6) become weaker upon occupancy of $\mathrm{CO}_{2}$ within the pores. Similar phenomena were also observed in MFM-401a. These results confirmed that $\mathrm{CO}_{2}$ is adsorbed in the pores of both materials, but because of the disordered $\mathrm{CO}_{2}$ molecules it was not possible to determine the location of $\mathrm{CO}_{2}$ accurately.

Modeling Methods. The adsorption isotherms for $\mathrm{CO}_{2}$ in MFM-400a and MFM-401a at $293 \mathrm{~K}$ up to 20 bar were simulated by GCMC methods. Three different types of all-atom generalized force field models were used. The first two, UFF ${ }^{17}$ and Dreiding, ${ }^{18}$ are widely used to predict $\mathrm{CO}_{2}$ uptake in $\mathrm{MOFs}^{19}$ and are parametrized to fit empirical observables (topdown). The third model, COMPASS, ${ }^{20}$ is of a different nature, as the potentials have been parametrized mostly using data from $\mathrm{ab}$ initio computations (bottom-up). Despite the diversity of these interatomic potential models, all three force fields showed selfconsistent results predicting a higher $\mathrm{CO}_{2}$ uptake for MFM-400a than MFM-401a at low pressures. Simulated isotherms are shown in Figure S7, and computational details, including further discussion of the force fields, are presented in the Supporting Information.

For a detailed investigation of the adsorption sites of $\mathrm{CO}_{2}$ in MFM-400a and MFM-401a, we performed periodic plane-wave DFT computations with periodic boundary conditions using the CP2K software. ${ }^{21}$ Detailed computational information is provided in the Supporting Information. Two types of DFT computations were performed: (1) Geometry optimizations relax the system to the local minimum-energy configuration. These simulations stabilize the $\mathrm{CO}_{2}$ at the adsorption site, enabling a prediction of the adsorption geometry and binding energy. Three different potential adsorption sites for $\mathrm{CO}_{2}$ were tested for stabilization: (i) end-on to the hydroxyl $\mathrm{H}$ atom, (ii) end-on to the $\mathrm{C}-\mathrm{H} \mathrm{H}$ atom, and (iii) bridged between the hydroxyl and $\mathrm{C}-\mathrm{H}$ groups. (2) Ab initio molecular dynamics (AIMD) simulations integrate Newton's equations of motion for the system as a function of time, allowing visualization of the movements of the $\mathrm{CO}_{2}$ molecules within the structure. From the recorded trajectories for each $\mathrm{CO}_{2}$-loaded material, the radial distribution functions (RDFs) between the $\mathrm{O}$ atom of $\mathrm{CO}_{2}$ and two different $\mathrm{H}$ atom types (hydroxyl and $\mathrm{C}-\mathrm{H}$ groups) were obtained. AIMD simulations were performed to identify adsorption sites from the geometry optimization computations while also taking into account the full loading and dynamics of the $\mathrm{CO}_{2}$ molecules. For the simulations, $20 \mathrm{CO}_{2}$ molecules were loaded into one unit cell of MFM-400a and $30 \mathrm{CO}_{2}$ molecules into $1 \times 1 \times 2$ unit cells of MFM-401a. A total of $20000 \mathrm{MD}$ steps with a time step of $0.5 \mathrm{fs}$ were run for each system, giving a total simulation length of $10.0 \mathrm{ps}$, which was sufficient to allow the gas molecules to relax and generate a sufficient statistical base to see well-defined coordination peaks in the RDFs.

For MFM-400a, the $\mathrm{CO}_{2}$ molecule stabilized at two separate sites. The first, more stable site (Figure 4a) shows $\mathrm{CO}_{2}$ binding via end-on coordination to the hydroxyl group $(\mathrm{O} \cdots \mathrm{H}-\mathrm{O}=$ $2.149 \AA$ ) with a binding energy of $33.5 \mathrm{~kJ} \mathrm{~mol}^{-1}$, consistent with 


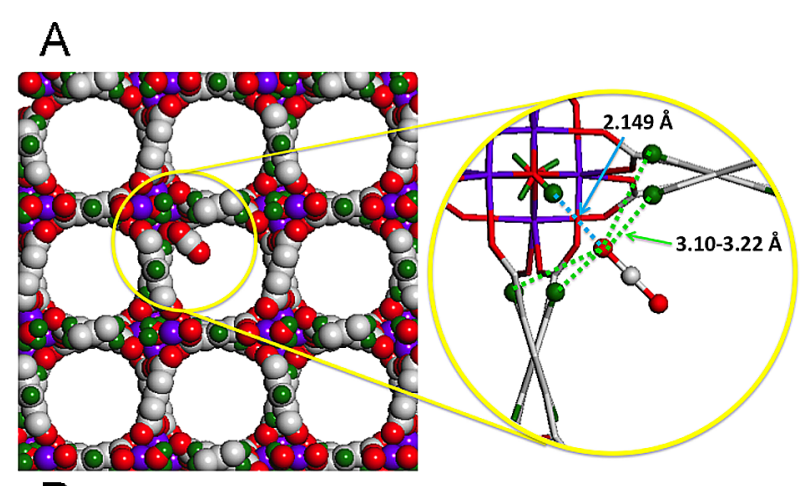

$\mathrm{B}$

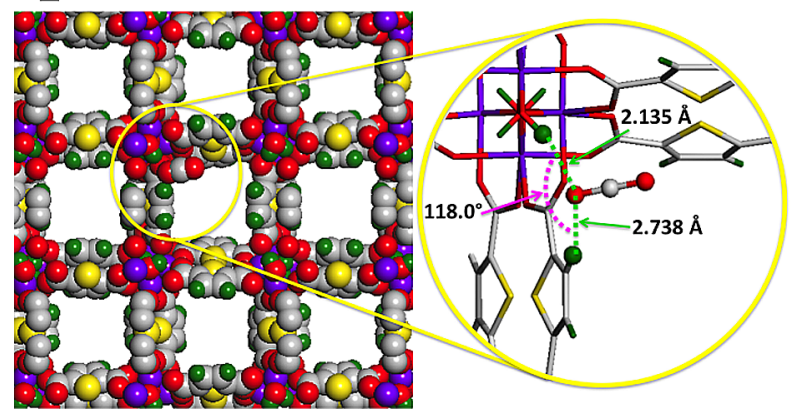

Figure 4. Adsorption sites for $\mathrm{CO}_{2}$ in (a) MFM-400a and (b) MFM$401 \mathrm{a}$ as predicted by DFT geometry optimization $(\mathrm{C}=$ gray, $\mathrm{O}=$ red, $\mathrm{H}$ $=$ green, $\mathrm{Sc}=$ purple, and $\mathrm{S}=$ yellow $)$.

the value of $29.5 \mathrm{~kJ} \mathrm{~mol}^{-1}$ estimated from the experimental adsorption isotherm (vide infra). In addition, this end-on coordination is stabilized by weak hydrogen-bonding interactions with the four surrounding aromatic $-\mathrm{CH}$ groups $(\mathrm{O} \cdots$ $\mathrm{H}-\mathrm{C}=3.10-3.22 \AA$ ), as shown in Figure 4a. This adsorption site is in accordance with that shown by Yang et al. ${ }^{16 \mathrm{~b}}$ for $\mathrm{CO}_{2}$ adsorption in the isostructural MOF MFM-300a(Al).

The second $\mathrm{CO}_{2}$ site stabilized in MFM-400a is at a bridging position between two - $\mathrm{CH}$ groups on each side of the functional group (ligand) at a position not within interaction proximity of the hydroxyl group. Here each $\mathrm{O}$ atom of the $\mathrm{CO}_{2}$ molecule interacts via weak hydrogen bonds to $-\mathrm{CH}$ groups $(\mathrm{O} 1 \cdots \mathrm{H} 1-$ $\mathrm{C} 1=3.077 \AA, \mathrm{O} 2 \cdots \mathrm{H} 2-\mathrm{C} 2=3.267 \AA$ ). This sorption site is weaker, with a binding energy of $20.4 \mathrm{~kJ} / \mathrm{mol}$. Thus, at very low $\mathrm{CO}_{2}$ loadings, the $\mathrm{CO}_{2}$ molecules occupy the more stable sites (the first site) with a binding energy of $33.5 \mathrm{~kJ} \mathrm{~mol}^{-1}$, and when these sites are completely occupied, the $\mathrm{CO}_{2}$ molecules then occupy the weaker sites (the second site) with a binding energy of $20.4 \mathrm{~kJ} / \mathrm{mol}$.

For MFM-401a, the geometry optimizations converged exclusively to one stable adsorption site for all of the starting configurations of the $\mathrm{CO}_{2}$ molecule. Interestingly, the $\mathrm{CO}_{2}$ molecule does not relax to an end-on coordination at the hydroxyl group in the same manner as for MFM-400a. Instead, the $\mathrm{O}$ atom of $\mathrm{CO}_{2}$ forms a cooperative interaction between the hydroxyl group $(\mathrm{O} \cdots \mathrm{H}-\mathrm{O}=2.135 \AA$ ) and one $\mathrm{C}-\mathrm{H}$ group $(\mathrm{O} \cdots$ $\mathrm{H}-\mathrm{C}=2.738 \AA$ ) at an $\mathrm{OH} \cdots \mathrm{O} \cdots \mathrm{HC}$ angle of $118.0^{\circ}$, as shown in Figure $4 \mathrm{~b}$. This tilted coordination to the hydroxyl group is explained by the fact that only one $-\mathrm{CH}$ group is close enough to interact with the bound $\mathrm{CO}_{2}$ molecule, and hence, double coordination is observed instead of the quintuple coordination in MFM-400a. The binding energy at this adsorption site was computed to be $37.3 \mathrm{~kJ} \mathrm{~mol}^{-1}$. This value is in good agreement with the value of $36.5 \mathrm{~kJ} \mathrm{~mol}^{-1}$ obtained from the adsorption isotherms for MFM-401a (vide infra).
Since MFM-400a incorporates more adsorption sites, it can accommodate $\mathrm{CO}_{2}$ molecules more efficiently than MFM-401a, resulting in a higher $\mathrm{CO}_{2}$ uptake. These stabilized adsorption sites were confirmed further by AIMD simulations, from which the $\mathrm{RDF}$ for the $\mathrm{O} \cdots \mathrm{H}-\mathrm{O}$ interactions (Figure 5) show

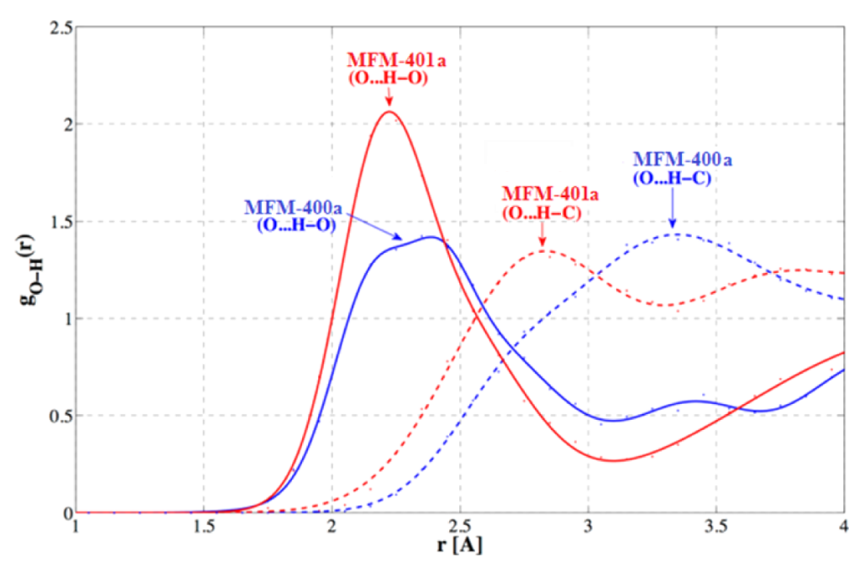

Figure 5. Radial distribution functions $\left(g_{\mathrm{O}-\mathrm{H}}(r)\right)$ for interactions of the $\mathrm{O}$ atom of the adsorbed $\mathrm{CO}_{2}$ molecules with the hydrogen-bond donors in MFM-400a and MFM-401a.

exclusive coordination peaks in good agreement with the stabilized $\mathrm{O} \cdots \mathrm{H}-\mathrm{O}$ distances. For MFM-401a, the RDF shows distinct maxima at 2.2 and $2.8 \AA$ for $\mathrm{O} \cdots \mathrm{H}-\mathrm{O}$ and $\mathrm{O} \cdots \mathrm{H}-\mathrm{C}$ interactions, respectively, corresponding well with the optimized distances for the doubly coordinated $\mathrm{CO}_{2}$ molecule. These distances from the RDF maxima are longer than the optimized values given above, which can be reasonably explained by the presence of other $\mathrm{CO}_{2}$ molecules in the system, as the interactions between the gas molecules would slightly decrease the strength of the interactions with the framework. The RDF for the $\mathrm{O} \cdots \mathrm{H}-\mathrm{O}$ interactions within MFM-400a is slightly broader and less smooth than that for MFM-401a, indicating that this adsorption site does not involve a single rigid interaction but rather has a dynamic character. This interpretation was further supported by visional analysis of the AIMD trajectories, which confirmed that the $\mathrm{CO}_{2}$ molecule alternates rapidly between the quintuple coordination and instantaneous double coordination to one of the four $-\mathrm{CH}$ groups.

To date, most of the molecular simulation studies on MOFs have focused on the adsorption of $\mathrm{H}_{2}, \mathrm{CO}_{2}$, and $\mathrm{CH}_{4}{ }^{22}$ However, very little attention has focused on the study of interactions of polar and nonpolar vapors with MOFs. ${ }^{23}$ We sought to obtain a broad view of the adsorption dynamics and energetics of hydrocarbon vapors in these porous materials and used various simulation methods in order to model different properties at different levels of theory. Force-field-based GCMC simulations were used to simulate the equilibrium uptake isotherms for each vapor in MFM-400a and MFM-401a. These simulations were performed using the atomistic Dreiding force field ${ }^{18}$ for the framework and the TRAPPE ${ }^{24}$ force field for the vapor molecules, a combination that has been shown to give reliable results for simulation of gas uptake in porous coordination polymers. ${ }^{23}$ These force fields describe the interatomic van der Waals forces using the 12-6 LennardJones functional form with the Lorentz-Berthelot mixing rules to combine unlike-atom-type Lennard-Jones parameters. Here the electrostatic forces were described by a Coulomb potential computed using the Ewald summation method, where the 

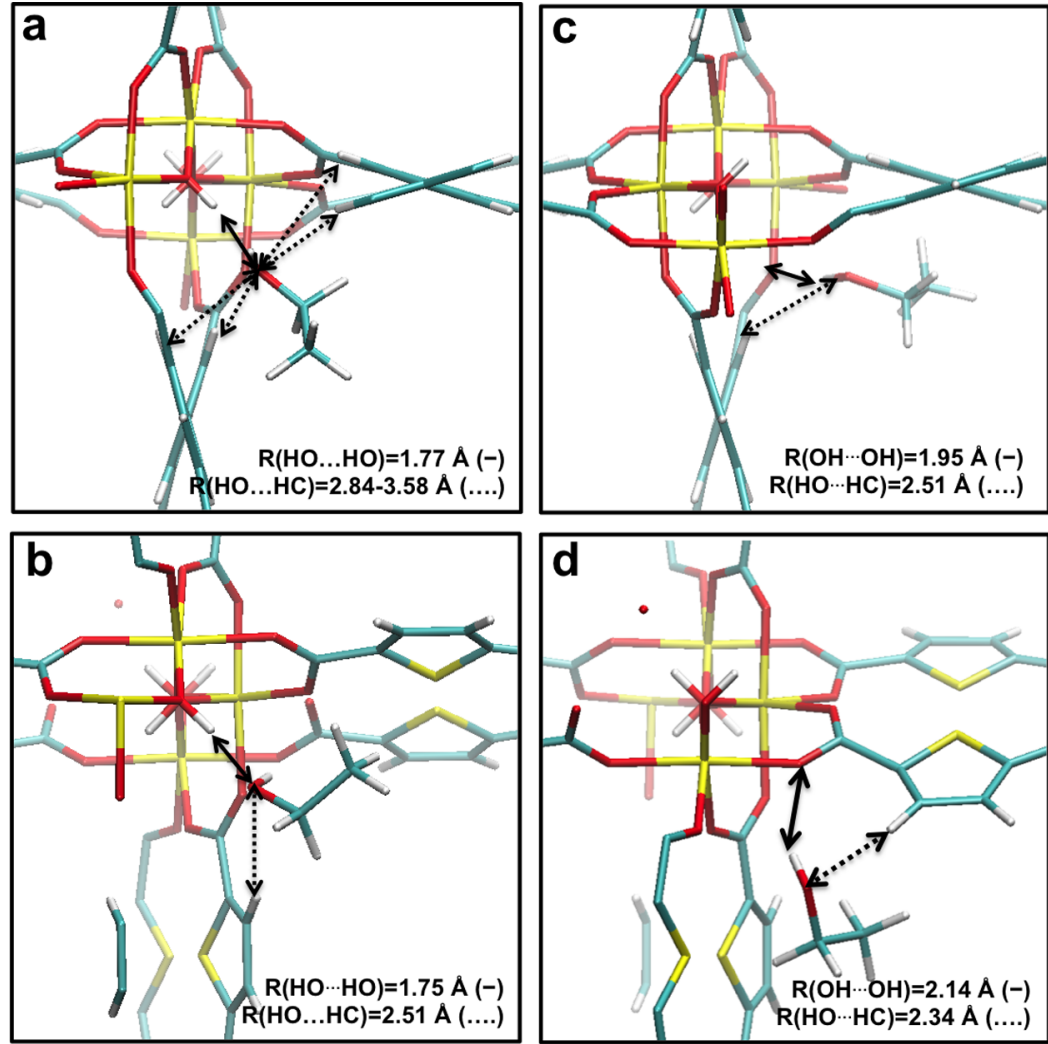

Figure 6. Adsorption sites for EtOH in (a, c) MFM-400a and (b, d) MFM-401a.
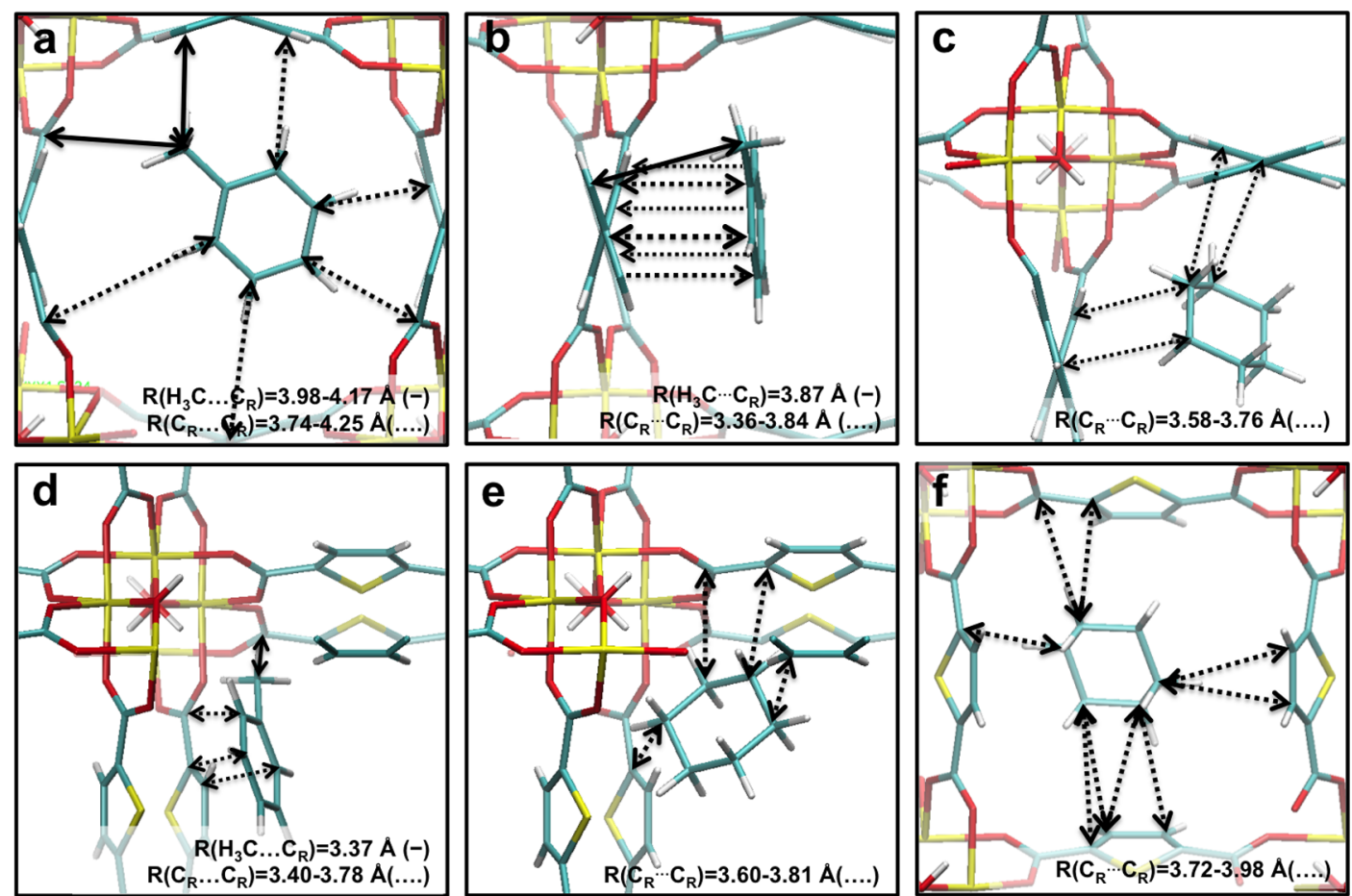

Figure 7. Adsorption sites for (a, b, d) toluene and (c, e, f) cyclohexane in (a, b, c) MFM-400a and (d, e, f) MFM-401a.

atomic partial charges were estimated from the DFT electronic wave functions through an electrostatic potential (ESP) fitting procedure with the DDEC algorithm. ${ }^{25}$ The isotherms were simulated at $298 \mathrm{~K}$ over the pressure ranges $0-100$ bar and $0-$ 1000 bar with 20 pressure points on a logarithmic scale. At each point, the simulation was allowed to equilibrate for $1 \times 10^{6} \mathrm{MC}$ steps, followed by a production run of $1 \times 10^{7} \mathrm{MC}$ steps from which the thermodynamic averages were computed. As can be seen in Figure S8, the simulated adsorption isotherms show a good correspondence with the experimental isotherms and support the substantial differences observed in the uptakes of polar EtOH and less-polar toluene and cyclohexane. This was 
found to be a result of the difference in hydrogen-bonding interactions with the hydroxyl groups in the frameworks. Furthermore, MFM-401a shows $10 \%$ higher uptakes compared with MFM-400a, consistent with the higher surface area measured in MFM-401a. For a more detailed investigation of the behavior of the adsorption at the molecular level, two types of DFT simulations were performed: (1) geometry optimizations, in order to investigate the geometries and heats of adsorption of the adsorbate at specific adsorption sites, and (2) DFT molecular dynamics (DFT-MD) simulations, allowing the dynamics of the system to be taken into account (see the Supporting Information). The DFT geometry optimization calculations showed the preferential adsorption site for EtOH in both MFM400a and MFM-401a to be the hydroxyl group within the framework. The oxygen atom of the $\mathrm{EtOH}$ molecule forms a strong hydrogen bond with the hydrogen atom of the hydroxyl group of the framework $\left(\mathrm{H}-\mathrm{O}_{\mathrm{EtOH}} \cdots \mathrm{H}-\mathrm{O}_{\mathrm{FW}}\right)$, with distances of $1.77 \AA$ (Figure 6a) and $1.75 \AA$ (Figure 6b), respectively. These strong interactions are also supported by the RDFs (Figure S9a), which show distinct coordination peaks at 1.85 and $1.75 \AA$ with coordination numbers of 0.73 and 0.69 for MFM-400a and MFM-401a, respectively. A second adsorption site for $\mathrm{EtOH}$ in the two structures with weaker hydrogen bonding was also localized. Here the hydrogen atom of the hydroxyl group in $\mathrm{EtOH}$ forms a strong hydrogen bond with an oxygen atom in the MFM-400a framework $\left(\mathrm{O}-\mathrm{H}_{\mathrm{EtOH}} \cdots \mathrm{O}_{\mathrm{FW}}=1.95 \AA\right.$ ), while the oxygen atom of $\mathrm{EtOH}$ interacts with a hydrogen atom of the proximate carbon ring in the framework $\left(\mathrm{H}-\mathrm{O}_{\mathrm{EtOH}} \cdots \mathrm{H}-\mathrm{C}_{\mathrm{FW}}=\right.$ $2.51 \AA$ ) (Figure 6c). In MFM-401a, the analogous distances are 2.14 and $2.34 \AA$, respectively (Figure 6d). In the RDFs for hydrogen bonding between EtOH molecules $\left(\mathrm{H}-\mathrm{O}_{\mathrm{EtOH}} \cdots \mathrm{H}-\right.$ $\mathrm{O}_{\mathrm{EtOH}}$; Figure S9a), clear coordination peaks are observed near $1.80 \AA$ in both MFM-400a and MFM-401a with coordination numbers of 0.46 and 0.37 , respectively.

For toluene and cyclohexane, several more nearly equivalent adsorption geometries are stabilized with small variances in their heats of adsorption. We thus focus our analysis on those sites identified as nonequivalent with the highest heats of adsorption. Following these criteria, we identify two adsorption sites for toluene in MFM-400a and one in MFM-401a, while for cyclohexane one and two sites are localized in the respective frameworks. These six sites are presented in Figure 7. The adsorption can be described primarily by $\pi-\pi$ interactions between aromatic moieties. Following this, we focus our structural analysis on the $\mathrm{C}_{\mathrm{FW}} \cdot{ }^{\cdots} \mathrm{C}_{\mathrm{Tol} / \mathrm{Cyc}}$ distances. In MFM$400 \mathrm{a}$, at the first, slightly stronger adsorption site, the toluene molecule lies horizontally in the center of the framework channel (Figure 7a). Here each carbon atom of the adsorbate lies at a distance of 3.74-4.25 ̊rom the closest framework atom. At the second site, the toluene ring lies parallel to the carbon ring of the framework (Figure $7 \mathrm{~b}$ ). The single stabilized site for toluene in MFM-401a (Figure 7d) is similar to the first toluene site in MFM-400a, with the toluene interacting with only one side of the pore wall at distances between 3.37 and $3.78 \AA$. Cyclohexane is stabilized close to the $\mathrm{Sc}$ (III) corner in both MFM-400a (Figure $7 \mathrm{c}$ ) and MFM-401a (Figure 7e) with $\mathrm{C}_{\mathrm{FW}} \cdots \mathrm{C}_{\mathrm{Tol} / \mathrm{Cyc}}$ distance ranges of $3.58-3.76 \AA$ and $3.60-3.81 \AA$, respectively. In MFM401 a, a centered adsorption site for cyclohexane is also stabilized (Figure 7f).

This DFT-based modeling study has helped us explain the differences in the uptakes of the three vapors with different sizes and polarities in MFM-400a and MFM-401a. The strong polarity of EtOH enhances the uptake greatly via formation of strong hydrogen bonds with the framework, primarily with the hydroxyl groups of MFM-400a and MFM-401a. In addition, the EtOH molecules interact with each other, further increasing the uptake capacity. This is in contrast to the bulkier and less polar aromatic molecules toluene and cyclohexane, which have larger diameters than $\mathrm{EtOH}$ and thus take up more of the pore volume compared with $\mathrm{EtOH}$.

Heat of Adsorption. An important parameter in the characterization of gas adsorption in porous hosts is the isosteric heat of adsorption $\left(Q_{s t}\right)$, which defines the binding energy of physisorption of the analyte in porous materials at different loadings. Thus, pure-component adsorption isotherms of $\mathrm{CO}_{2}$ and $\mathrm{CH}_{4}$ were obtained for MFM-400a and MFM-401a at 273 and $293 \mathrm{~K}$ from 0 to $1 \mathrm{bar}$, and the data were analyzed using a virial-type equation (Figures S10-S17). ${ }^{26}$ The value of $\ln (n / P)$ for a given amount adsorbed $(n)$ was calculated by linear regression from the virial equation analysis using the following virial equation:

$$
\ln \left(\frac{n}{P}\right)=A_{0}+A_{1} n+A_{2} n^{2}+\cdots
$$

where $P$ is the pressure, $n$ is the amount adsorbed, and $A_{0}, A_{1}$, etc. are virial coefficients. $A_{0}$ is related to the adsorbate-adsorbent interactions, while $A_{1}$ describes adsorbate-adsorbate interactions. ${ }^{26}$ At low surface coverage, $A_{2}$ and higher terms can be ignored, so a graph of $\ln (n / P)$ versus $n$ should give a straight line at low surface coverage. Thus, from the virial equation (eq 1 ) and the Clausius-Clapeyron equation (eq 2),

$$
\left(\frac{\partial \ln P}{\partial T}\right)_{\theta}=\frac{Q_{\text {st }}}{R T^{2}}
$$

the isosteric heat of adsorption $\left(Q_{s t}\right)$ can be calculated. The isosteric heats of adsorption of $\mathrm{CO}_{2}$ and $\mathrm{CH}_{4}$ for MFM-400a and MFM-401a at zero surface coverage are presented in Table 1. The values of the heats of adsorption for both analytes were calculated to be higher for MFM-401a than for MFM-400a (Figures S18-S21). This result is consistent with the pore size distributions of the two materials, ${ }^{13}$ i.e., the pore size of MFM401a is smaller (6.3 $\AA$ ) than that of MFM-400a (8.1 $\AA$ ). Thus, when the pores are narrow, the binding energy of the analyte $\left(\mathrm{CO}_{2}\right.$ or $\left.\mathrm{CH}_{4}\right)$ is enhanced at low loadings, ${ }^{27}$ which is reflected in an increase in the value of $Q_{s t}$. Interestingly, MFM-400a shows higher $\mathrm{CO}_{2}$ uptakes than MFM-401a (vide supra) and yet a lower heat of adsorption of $\mathrm{CO}_{2}$. A linear correlation of a high $\mathrm{CO}_{2}$ uptake with a high $\mathrm{CO}_{2}$ heat of adsorption is commonly expected. However, in this case the $\mathrm{CO}_{2}$ capacity is directly correlated with the number (or density) of preferential adsorption sites. Thus, by efficiently accommodating $\mathrm{CO}_{2}$ molecules into two adsorption sites rather than just one, MFM-400a exhibits higher $\mathrm{CO}_{2}$ uptakes than MFM-401a.

The isosteric heats of adsorption of $\mathrm{CH}_{4}$ in MFM-400a and MFM-401a are consistent with those of other porous metalorganic materials, ${ }^{28}$ and interestingly, both showed a moderate $Q_{\mathrm{st}}$ for $\mathrm{CO}_{2}$, a desirable feature to minimize the energy penalty for regeneration of the free porous host. ${ }^{1 \mathrm{~b}, 2}$ The value of $Q_{\mathrm{st}}$ for $\mathrm{CO}_{2}$ in MFM-300a is approximately $30.0 \mathrm{~kJ} \mathrm{~mol}^{-1},{ }^{16}$ in good agreement with the value calculated for MFM-400a $(29.5 \mathrm{~kJ}$ $\mathrm{mol}^{-1}$ ) and consistent with the fact that these materials are isostructural and exhibit similar $\mathrm{CO}_{2}$ adsorption properties.

Adsorption Selectivity for $\mathrm{CO}_{2}$. The simplest method to evaluate the adsorption selectivity for $\mathrm{CO}_{2}$ from a gas mixture is to calculate a selectivity factor using the experimental single- 
component gas adsorption isotherms. The selectivity factor $(\alpha)^{2}$ is the molar ratio of the adsorption amounts at the relevant partial pressures of the gases. The expression used is

$$
\alpha=\frac{n_{x} P_{y}}{n_{y} P_{x}}
$$

where $n_{x}$ is the amount of gas of component $x$ adsorbed at a predefined pressure and $P_{x}$ is the partial pressure of component $x$. In order to make a comparison of the $\mathrm{CO}_{2} / \mathrm{N}_{2}$ selectivities of our materials to those of several reference materials, $\mathrm{CO}_{2}$ and $\mathrm{N}_{2}$ adsorption experiments were performed at $298 \mathrm{~K}$ and 1 bar on MFM-400a and MFM-401a (Figure 8). Table 2 shows the results
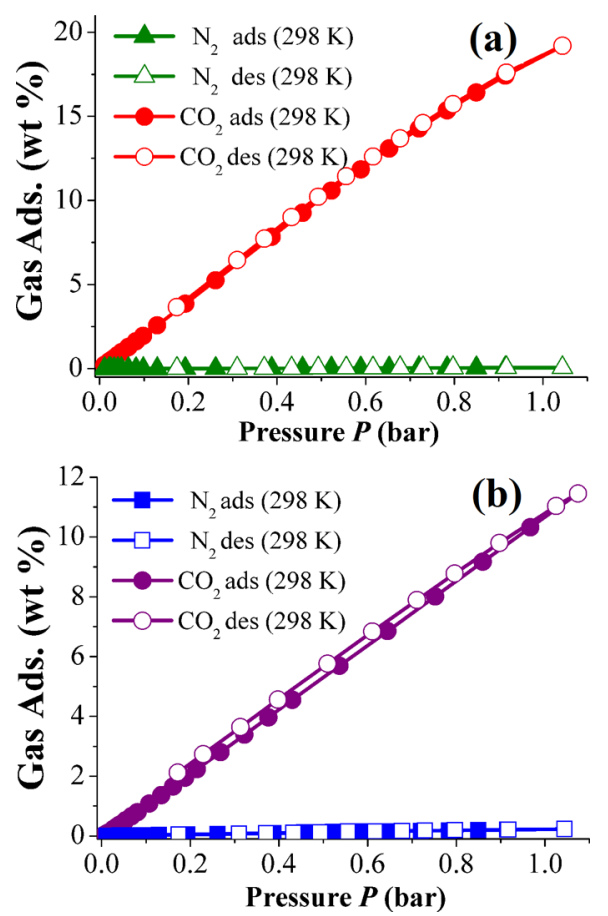

Figure 8. Adsorption isotherms for $\mathrm{CO}_{2}$ and $\mathrm{N}_{2}$ in (a) MFM-400a and (b) MFM-401a up to 1 bar at $298 \mathrm{~K}$.

Table 2. $\mathrm{CO}_{2} / \mathrm{N}_{2}$ Selectivities $(\alpha)$ for MFM-400a and MFM401a Compared with Those for Reference Materials at $298 \mathrm{~K}$

\begin{tabular}{|c|c|c|}
\hline material & $\alpha$ & $\mathrm{CO}_{2}$ uptake at $0.15 \mathrm{bar}(\mathrm{wt} \%)$ \\
\hline MFM-400 & 76 & 3.8 \\
\hline MFM-401 & 25 & 1.6 \\
\hline $\mathrm{Mg}_{2}(\mathrm{dobdc})^{29}$ & 30 & 21.2 \\
\hline en-Cu-BTTri ${ }^{8 a}$ & 44 & 2.3 \\
\hline $\mathrm{Zn}_{2}(\mathrm{BTetB})\left(\mathrm{py}-\mathrm{CF}_{3}\right)_{2}{ }^{30}$ & 50 & 0.9 \\
\hline bio-MOF-11 $11^{31}$ & 65 & 5.4 \\
\hline mmen- $\mathrm{Mg}_{2}(\mathrm{dobdc})^{32}$ & 200 & 22.0 \\
\hline SIFSIX-2-Cu-i ${ }^{4 \mathrm{f}}$ & 72 & 7.6 \\
\hline SIFSIX-3-Cu ${ }^{4 g}$ & 39 & 11 \\
\hline PEI-MIL-101 $1^{33}$ & 770 & 18.5 \\
\hline UTSA- $16^{34}$ & 83 & 19.0 \\
\hline MAF-X25ox ${ }^{35}$ & 262 & 13.4 \\
\hline
\end{tabular}

of the selectivity calculations for MFM-400a and MFM-401a at $298 \mathrm{~K}$ compared with the selectivity factors for the reference materials. These results show that MFM-400a exhibits a relatively modest $\mathrm{CO}_{2} / \mathrm{N}_{2}$ selectivity of 76 (Table 2 and Figure $8 \mathrm{a})$. Remarkably, Chen and co-workers ${ }^{33}$ reported a post- synthetic modification of the material entitled MIL-101 by the incorporation of polyethylenimine (PEI-MIL-100) and estimated a ultrahigh selectivity for $\mathrm{CO}_{2}$ over $\mathrm{N}_{2}$ of 770 .

Cyclability of $\mathrm{CO}_{2}$ Adsorption. To test the gas adsorptiondesorption recyclability of MFM-400a and MFM-401a, $\mathrm{CO}_{2}$ gas sorption isotherms were measured for 10.5 cycles at $293 \mathrm{~K}$ and 1 bar (Figures S26 and S27). These results showed no apparent decrease in capacity over 10.5 cycles and revealed the complete regeneration of the material solely by evacuation for only $30 \mathrm{~min}$ without any application of heat.

\section{CONCLUSIONS}

MFM-400a and MFM-401a display selective and reversible sequestration of $\mathrm{CO}_{2}$. In particular, MFM-400a shows a reasonable $\mathrm{CO}_{2}$ uptake at low pressure and a competitive $\mathrm{CO}_{2} / \mathrm{N}_{2}$ selectivity for a metal-organic material. Both porous materials exhibit moderate heats of adsorption for $\mathrm{CO}_{2}$, which provides a facile "uptake-release" system that is ideal for $\mathrm{CO}_{2}$ capture. Interestingly, experimental $\mathrm{CO}_{2}$ adsorption isotherms at low pressure showed a higher $\mathrm{CO}_{2}$ uptake for MFM-400a than MFM-401a. This experimental uptake was confirmed by GCMC simulations, where three different types of all-atom generalized force field models all confirmed a higher $\mathrm{CO}_{2}$ uptake for MFM400a. Further, DFT computations performed on $\mathrm{CO}_{2}$ molecules within the porous materials revealed detailed interaction information. For MFM-400a, the $\mathrm{CO}_{2}$ molecule is stabilized at two different sites. The more stable site is at the $\mathrm{Sc}-\mathrm{OH}$ group, which participates in moderate interactions with $\mathrm{CO}_{2}$, and these interactions are complemented by weak hydrogen-bonding interactions from four surrounding aromatic $-\mathrm{CH}$ groups. The calculated binding energy of this site is $33.5 \mathrm{~kJ} \mathrm{~mol}^{-1}$, in good agreement with the experimental $Q_{s t}$ value of $29.5 \mathrm{~kJ} \mathrm{~mol}^{-1}$ obtained from the gas isotherm. In the case of MFM-401a, there is only one stable adsorption site that arises from a cooperative interaction of $\mathrm{CO}_{2}$ with the $\mathrm{Sc}-\mathrm{OH}$ group and one $\mathrm{C}-\mathrm{H}$ group. This binding energy was computed to be $37.3 \mathrm{~kJ} \mathrm{~mol}^{-1}$,in good agreement with the experimental $Q_{\mathrm{st}}$ value of $36.5 \mathrm{~kJ} \mathrm{~mol}^{-1}$. Selective vapor sorption at ambient temperature by highly porous coordination polymers is a largely unexplored potential application. Both MFM-400a and MFM-401a showed high selectivity for EtOH vapor over nonpolar toluene and cyclohexane vapors, and the experimental uptakes were supported by GCMC simulations. DFT computations showed that as a result of the high polarity of EtOH molecules, strong hydrogen bonds are formed primarily with the hydrogen atoms of the hydroxyl groups of MFM-400a and MFM-401a $\left(\mathrm{H}-\mathrm{O}_{\mathrm{EtOH}} \cdots \mathrm{H}-\mathrm{O}_{\mathrm{FW}}\right)$ with distances of 1.77 and $1.75 \AA$, respectively. Thus, these porous materials are promising candidates for capture of polar VOCs. Finally, the exceptional gas uptake regeneration that these materials showed can afford minimal economic and environmental penalties without decreases in either capacity or selectivity.

\section{ASSOCIATED CONTENT}

\section{Supporting Information}

The Supporting Information is available free of charge on the ACS Publications website at DOI: 10.1021/acs.inorgchem.6b00035.

Gas adsorption data, in situ synchrotron X-ray powder diffraction data, GCMC simulations, DFT computations, geometry optimization calculations, AIMD simulations, calculations of isosteric heats of adsorption, variation of 
adsorption enthalpy with gas loading, and cyclability of $\mathrm{CO}_{2}$ adsorption $(\mathrm{PDF})$

\section{AUTHOR INFORMATION}

\section{Corresponding Authors}

*E-mail: argel@unam.mx

*E-mail: m.schroder@manchester.ac.uk

*E-mail:xzou@mmk.su.se

\section{Notes}

The authors declare no competing financial interest.

\section{ACKNOWLEDGMENTS}

This project was supported by the Swedish Research Council (VR) and the Swedish Government Agency for Innovation Systems (VINNOVA) through the Berzelii Centre EXSELENT. I.A.I. gratefully acknowledges the Wenner-Gren Foundation (Sweden) for the Research Fellow Grant and CONACyT (212318) and PAPIIT UNAM (IN100415), Mexico, for financial support. A.M. thanks the Swedish National Institute of Computations (SNIC) for allocation of computing time and the Center of Parallel Computers (PDC). A.L. acknowledges the Swedish Research Council for financial support. J.-S.C. and S.L. are grateful to the Center for Hybrid Interface Materials (HIM) for the Global Frontier R\&D Program (2013-073298), funded by the Ministry of Science, ICT \& Future Planning. M.S. and S.Y. thank the EPSRC, the ERC, Leverhulme Trust, and the Universities of Nottingham and Manchester for support. The authors are grateful to the European Synchrotron Radiation Facility (ESRF) for access to beamline ID11 and to U. Winnberg (ITAM) for scientific discussions.

\section{REFERENCES}

(1) (a) Lipfert, F. W. Air Pollution and Community Health: A Critical Review and Data Source Book; Van Nostrand Reinhold: New York, 1994. (b) D’Alessandro, D. M.; Smit, B.; Long, J. R. Angew. Chem., Int. Ed. 2010, 49, 6058-6082.

(2) Sumida, K.; Rogow, D. L.; Mason, J. A.; McDonald, T. M.; Bloch, E. D.; Herm, Z. R.; Bae, T.-H.; Long, J. R. Chem. Rev. 2012, 112, 724-781.

(3) Makal, T. A.; Li, J.-R.; Lu, W.; Zhou, H.-C. Chem. Soc. Rev. 2012, 41, 7761-7779.

(4) (a) Yang, S.; Martin, G. S. B.; Titman, J. J.; Blake, A. J.; Allan, D. R.; Champness, N. R.; Schröder, M. Inorg. Chem. 2011, 50, 9374-9384.

(b) Yang, S.; Lin, X.; Blake, A. J.; Walker, G. S.; Hubberstey, P.; Champness, N. R; Schröder, M. Nat. Chem. 2009, 1, 487-493. (c) Nuñez, A. J.; Shear, L. N.; Dahal, N.; Ibarra, I. A.; Yoon, J. W.; Hwang, Y. K.; Chang, J.-S.; Humphrey, S. M. Chem. Commun. 2011, 47, 11855-11857. (d) Ibarra, I. A.; Tan, K. E.; Lynch, V. M.; Humphrey, S. M. Dalton Trans. 2012, 41, 3920-3923. (e) Lin, X.; Telepeni, I.; Blake, A. J.; Dailly, A.; Brown, C. M.; Simmons, J. M.; Zoppi, M.; Walker, G. S.; Thomas, K. M.; Mays, T. J.; Hubberstey, P.; Champness, N. R.; Schröder, M. J. Am. Chem. Soc. 2009, 131, 2159-2171. (f) Nugent, P.; Belmabkhout, Y.; Burd, S. D.; Cairns, A. J.; Luebke, R.; Forrest, K.; Pham, T.; Ma, S.; Space, B.; Wojtas, L.; Eddaoudi, M.; Zaworotko, M. J. Nature 2013, 495, 80-84. (g) Shekhah, O.; Belmabkhout, Y.; Chen, Z.; Guillerm, V.; Cairns, A.; Adil, K.; Eddaoudi, M. Nat. Commun. 2014, 5, 4228. (h) Tozawa, T.; Jones, J. T. A.; Swamy, S. I.; Jiang, S.; Adams, D. J.; Shakespeare, S.; Clowes, R.; Bradshaw, D.; Hasell, T.; Chong, S. Y.; Tang, C.; Thompson, S.; Parker, J.; Trewin, A.; Bacsa, J.; Slawin, A. M. Z.; Steiner, A.; Cooper, A. I. Nat. Mater. 2009, 8, 973-978. (i) Dawson, R.; Adams, D. J.; Cooper, A. I. Chem. Sci. 2011, 2, 1173-1177.

(5) (a) Furukawa, H.; Ko, N.; Go, Y. B.; Aratani, N.; Choi, S. B.; Choi, E.; Yazaydin, A. Ö.; Snurr, R. Q.; O’Keeffe, M.; Kim, J.; Yaghi, O. M. Science 2010, 329, 424-428. (b) Bohnsack, A. M.; Ibarra, I. A.; Hatfield, P. W.; Yoon, J. W.; Hwang, Y. K.; Chang, J.-S.; Humphrey, S. M. Chem. Commun. 2011, 47, 4899-4901.
(6) Millward, A. R.; Yaghi, O. M. J. Am. Chem. Soc. 2005, 127, 1799817999.

(7) Suh, M. P.; Park, H. J.; Prasad, T. K.; Lim, D.-W. Chem. Rev. 2012, $112,782-835$.

(8) (a) Demessence, A.; D’Alessandro, D. M.; Foo, M. L.; Long, J. R. J. Am. Chem. Soc. 2009, 131, 8784-8786. (b) Zhang, J.-P.; Chen, X.-M. J. Am. Chem. Soc. 2009, 131, 5516-5521.

(9) Vaidhyanathan, R.; Iremonger, S. S.; Shimizu, G. K. H.; Boyd, P. G.; Alavi, S.; Woo, T. K. Science 2010, 330, 650-653.

(10) Pachfule, P.; Banerjee, R. Cryst. Growth Des. 2011, 11, 51765181.

(11) Llewellyn, P. L.; Bourrelly, S.; Serre, C.; Vimont, A.; Daturi, M.; Hamon, L.; De Weireld, G.; Chang, J.-S.; Hong, D.-Y.; Hwang, Y. K.; Jhung, S. H.; Férey, G. Langmuir 2008, 24, 7245-7250.

(12) Zhao, D.; Yuan, D.; Zhou, H.-C. Energy Environ. Sci. 2008, 1, 222235.

(13) Ibarra, I. A.; Yang, S.; Lin, X.; Blake, A. J.; Rizkallah, P. J.; Nowell, H.; Allan, D. R.; Champness, N. R.; Hubberstey, P.; Schröder, M. Chem. Commun. 2011, 47, 8304-8306.

(14) Rouquerol, J.; Llewellyn, P.; Rouquerol, F. Stud. Surf. Sci. Catal. 2007, 160, 49-56.

(15) Walton, K. S.; Snurr, R. Q. J. Am. Chem. Soc. 2007, 129, 85528556.

(16) (a) Yang, S.; Sun, J.; Ramirez-Cuesta, A. J.; Callear, S. K.; David, W. I. F.; Anderson, D. P.; Newby, R.; Blake, A. J.; Parker, J. E.; Tang, C. C.; Schröder, M. Nat. Chem. 2012, 4, 887-894. (b) Yang, S.; RamirezCuesta, A. J.; Newby, R.; Garcia-Sakai, V.; Manuel, P.; Callear, S. K.; Campbell, S. I.; Tang, C. C.; Schröder, M. Nat. Chem. 2015, 7, 121-129.

(17) Rappé, A. K.; Casewit, C. J.; Colwell, K. S.; Goddard, W. A., III; Skiff, W. M. J. Am. Chem. Soc. 1992, 114, 10024-10035.

(18) Mayo, S. L.; Olafson, B. D.; Goddard, W. A., III J. Phys. Chem. 1990, 94, 8897-8909.

(19) (a) Düren, T.; Bae, Y.-S.; Snurr, R. Q. Chem. Soc. Rev. 2009, 38, 1237-1247. (b) Yazaydin, A. Ö.; Snurr, R. Q.; Park, T.-H.; Koh, K.; Liu, J.; LeVan, M. D.; Benin, A. I.; Jakubczak, P.; Lanuza, M.; Galloway, D. B.; Low, J. J.; Willis, R. R. J. Am. Chem. Soc. 2009, 131, 18198-18199. (c) Wells, B. A.; Chaffee, A. L. Adsorption 2011, 17, 255-264. (d) Li, J.R.; Ma, Y.; McCarthy, M. C.; Sculley, J.; Yu, J.; Jeong, H.-K.; Balbuena, P. B.; Zhou, H.-C. Coord. Chem. Rev. 2011, 255, 1791-1823. (e) Chang, B. K.; Bristowe, P. D.; Cheetham, A. K. Phys. Chem. Chem. Phys. 2013, 15, 176-182. (f) Burtch, N. C.; Jasuja, H.; Dubbeldam, D.; Walton, K. S. J. Am. Chem. Soc. 2013, 135, 7172-7180.

(20) Sun, H. J. Phys. Chem. B 1998, 102, 7338-7364.

(21) www.cp2k.org (accessed Oct 20, 2015).

(22) (a) Arici, M.; Yeşilel, O. Z.; Keskin, S.; Taş, M. Polyhedron 2012, 45, 103-106. (b) Haldoupis, E.; Watanabe, T.; Nair, S.; Sholl, D. S. ChemPhysChem 2012, 13, 3449-3452. (c) Salles, F.; Jobic, H.; Devic, T.; Llewellyn, P. L.; Serre, C.; Férey, G.; Maurin, G. ACS Nano 2010, 4, $143-152$.

(23) (a) Sun, J.-K.; Yao, Q.-X.; Tian, Y.-Y.; Wu, L.; Zhu, G.-S.; Chen, R.-P.; Zhang, J. Chem. - Eur. J. 2012, 18, 1924-1931. (b) Ibarra, I. A.; Yoon, J. W.; Chang, J.-S.; Lee, S. K.; Lynch, V. M.; Humphrey, S. M. Inorg. Chem. 2012, 51, 12242-12247. (c) Lin, X.; Blake, A. J.; Wilson, C.; Sun, X. Z.; Champness, N. R.; George, M. G.; Hubberstey, P.; Mokaya, R; Schröder, M. J. Am. Chem. Soc. 2006, 128, 10745-10753.

(24) Potoff, J. J.; Siepmann, J. I. AIChE J. 2001, 47, 1676-1682.

(25) Manz, T. A.; Sholl, D. S. J. Chem. Theory Comput. 2012, 8, 28442867.

(26) (a) Zhao, X.; Villar-Rodil, S.; Fletcher, A. J.; Thomas, K. M. J. Phys. Chem. B 2006, 110, 9947-9955. (b) Zhao, X. B.; Xiao, B.; Fletcher, A. J.; Thomas, K. M. J. Phys. Chem. B 2005, 109, 8880-8888. (c) O'koye, I. P.; Benham, M.; Thomas, K. M. Langmuir 1997, 13, 4054-4059. (d) Reid, C. R.; Thomas, K. M. Langmuir 1999, 15, 3206-3218. (e) Reid, C. R.; Thomas, K. M. J. Phys. Chem. B 2001, 105, 10619-10629.

(27) (a) Chun, H.; Dybtsev, D. N.; Kim, H.; Kim, K. Chem. - Eur. J. 2005, 11, 3521-3529. (b) Ibarra, I. A.; Bayliss, P. A.; Pérez, E.; Yang, S.; Blake, A. J.; Nowell, H.; Allan, D. R.; Poliakoff, M.; Schröder, M. Green Chem. 2012, 14, 117-122. (c) Bayliss, P. A.; Ibarra, I. A.; Pérez, E.; Yang, 
S.; Tang, C. C.; Poliakoff, M.; Schröder, M. Green Chem. 2014, 16, 3796-3802.

(28) Peng, Y.; Krungleviciute, V.; Eryazici, I.; Hupp, J. T.; Farha, O. K.; Yildirim, T. J. Am. Chem. Soc. 2013, 135, 11887-11894.

(29) (a) Dietzel, P. D. C.; Besikiotis, V.; Blom, R. J. Mater. Chem. 2009, 19, 7362-7370. (b) Yazaydin, A. Ö.; Snurr, R. Q.; Park, T. H.; Koh, K.; Liu, J.; LeVan, M. D.; Benin, A. I.; Jakubczak, P.; Lanuza, M.; Galloway, D. B.; Low, J. J.; Willis, R. R. J. Am. Chem. Soc. 2009, 131, 18198-18199.

(30) Bae, Y.-S.; Farha, O. K.; Hupp, J. T.; Snurr, R. Q. J. Mater. Chem. 2009, 19, 2131-2134.

(31) An, J.; Geib, S. J.; Rosi, N. L. J. Am. Chem. Soc. 2010, 132, 38-39. (32) McDonald, T. M.; Lee, W. R.; Mason, J. A.; Wiers, B. M.; Hong, C. S.; Long, J. R. J. Am. Chem. Soc. 2012, 134, 7056-7065.

(33) Lin, Y.; Yan, Q.; Kong, C.; Chen, L. Sci. Rep. 2013, 3, 1859.

(34) (a) Xiang, S.; He, Y.; Zhang, Z.; Wu, H.; Zhou, W.; Krishna, R.; Chen, B. Nat. Commun. 2012, 3, 954-962. (b) Zhang, Z.; Yao, Z.-Z.; Xiang, S.; Chen, B. Energy Environ. Sci. 2014, 7, 2868-2899.

(35) Liao, P.-Q.; Chen, H.; Zhou, D.-D.; Liu, S.-Y.; He, C.-T.; Rui, Z.; Ji, H.; Zhang, J.-P.; Chen, X.-M. Energy Environ. Sci. 2015, 8, 1011-1016. 